\title{
DESIGN, GÊNERO E PODER: OPRESSÃO DO DISCURSO HEGEMÔNICO SOBRE O CORPO FEMININO E ESTRATÉGIAS DE TRANSGRESSÃO POR MULHERES COM CÂNCER DE MAMA
}

\author{
Débora Ferro (discente)/UFPE \\ Walter Correia (orientador)/UFPE \\ Kátia Araújo (co-orientadora)/UFPE
}

\section{RESUMO}

Este artigo enfoca questões de gênero e poder no campo do design, relacionando-as à mulher e ao corpo feminino. Em contextos culturais onde predomina um pensamento patriarcal, o corpo feminino é frequentemente objetificado e as transformações corporais (a exemplo do câncer de mama) fazem com que esse corpo-objeto deixe de atender às idealizações operadas pelo sistema vigente, reforçando ainda mais a sensação de desconformidade experimentada pelas mulheres. Propomos contribuir com a temática à luz das teorias propostas pelas autoras Michelle Perrot (2007) e Teresa de Lauretis (1994). Por meio da reflexão sobre dados empíricos de uma busca preliminar, pretendemos reconhecer algumas tecnologias de gênero e perceber estratégias que as mulheres utilizam para lidar com o gendramento do mundo e, ao mesmo tempo, escapar deste lugar engendrado, seja por meio do uso de artefatos, seja através da ressignificação do olhar para si mesmas.

Palavras-chave: artefatos; corpo feminino; câncer de mama; autoimagem; tecnologias de gênero.

\section{Introdução}

Muito se tem discutido sobre a objetificação do corpo feminino, em especial naqueles contextos culturais nos quais predomina um pensamento patriarcal, e onde a mulher e sua imagem são frequentemente reduzidas ao status de objeto. Em nossa pesquisa doutoral, temos buscado compreender o papel dos artefatos no processo de ressignificação da autoimagem por mulheres mastectomizadas. Nesse sentido, parte de nossas reflexões consiste em perceber as relações de poder que se estabelecem a respeito da mulher e do corpo feminino, particularmente de mulheres que passaram pela experiência do câncer de mama.

Somadas às relações de poder que emergem do sistema sexo-gênero, outras formas de domínio e opressão baseadas em fatores como raça e classe social também são determinantes para a forma como as mulheres lidam com o próprio corpo. Isso se evidencia quando, em virtude de circunstâncias 
adversas (a exemplo do câncer), parte desse corpo-objeto deixa de atender às idealizações operadas pelo sistema vigente.

De modo geral, ao descobrir um câncer, a autoestima das mulheres é claramente afetada, assim como certos elementos de sua identidade, intimamente relacionados à percepção de sua autoimagem. Desse modo, durante o enfrentamento à doença, além do tratamento em si, é possível observar uma busca por estratégias que visam resgatar aspectos dessa identidade, ao mesmo tempo em que tentam elevar sua autoestima, seja por meio do uso de artefatos - preservando ou omitindo características estéticas desse corpo que vem passando por mudanças significativas -, seja através da ressignificação do olhar para si mesmas.

Embora o Design, enquanto campo de atuação, costume privilegiar o desenvolvimento projetual a partir de uma perspectiva essencialmente pragmática e orientada pela visão hegemônica do sistema sexo-gênero, o foco desta pesquisa incide no valor simbólico do Design e das percepções que emergem a partir do uso (ou não uso) dos artefatos em benefício das próprias mulheres. Este é, portanto, o objeto aqui explorado.

\section{Referencial teórico}

Na discussão deste artigo, propomos contribuir com a temática à luz das teorias propostas por Michelle Perrot (2007), e Teresa de Lauretis (1994), autoras do campo dos estudos de gênero, representativas da perspectiva feminista.

Perrot (2007) aborda o corpo das mulheres e suas transformações ao longo da história, considerando não uma perspectiva abstrata da "Mulher", mas a história de vida de mulheres reais em seus contextos socioculturais específicos e a percepção social quanto aos reflexos do tempo em suas características corporais. Em suas reflexões, a autora evidencia que ao longo da história, "a mulher é, antes de tudo, uma imagem. Um rosto, um corpo, vestido ou nu. A mulher é feita de aparências." (PERROT, 2007, p. 49). Além disso, relata como partes do corpo feminino são diferentemente valorizadas a depender da época, indicando como a mulher figura como um corpo partido, fracionado, independentemente do período histórico:

Até o século XIX, perscruta-se a parte superior, o rosto, depois o busto; há pouco interesse pelas pernas. Depois o olhar desloca-se para a parte inferior, os vestidos se ajustam mais à cintura, as bainhas descobrem os tornozelos. No século XX, as pernas entram em cena, haja vista a valorização das pernas longilíneas nas peças publicitárias. Progressivamente, a busca da esbeltez, a obsessão quase anoréxica 
pela magreza sucedem à atração pelas generosas formas arredondadas da "bela mulher" de 1900. (PERROT, 2007, p.50).

Como contribuição à luta feminista, Perrot (2007) também destaca a importância de iniciativas que tragam visibilidade às ações das mulheres, incluindo tanto o registro de sua presença em diferentes momentos históricos, quanto as análises de contextos, denunciando a opressão e legitimando protagonismos, resistências, bem como o autorreconhecimento de suas prerrogativas, força e empoderamento.

Lauretis (1994), por sua vez, traz à tona o conceito de tecnologias de gênero, com uma ampla reflexão sobre o sistema sexo-gênero, indicando que "a construção do gênero ocorre hoje através das várias tecnologias do gênero (p. ex., o cinema) e discursos institucionais (p. ex., a teoria)" Nesse contexto, a própria teoria, com sua capacidade de "controlar o campo do significado social e assim produzir, promover e "implantar" representações de gênero" pode também ser considerada uma tecnologia de gênero (LAURETIS, 1994, p. 228). Tais elementos, a nosso ver, são ferramentas que embasam o design não apenas como processo, mas como linguagem e discurso.

As elaborações da autora, embora inspiradas nas contribuições de Althusser, que pressupõe um sujeito preso à ideologia, sugerem que é possível transgredir a lógica hegemônica dos dispositivos culturais que vinculam o gênero e toda sua narrativa simbólica ao sexo natural, desde que as tecnologias sejam também construídas a partir de uma ótica feminina. Como condição para a existência do feminismo, ela destaca a contradição que incide em ocupar um lugar engendrado e, ao mesmo tempo, perceber e questionar a heteronomia dos sistemas sociais. A consciência dessa contradição é o que viabilizaria às mulheres se moverem em direção a tecnologias mais favoráveis a seus próprios interesses.

Para a presente construção, selecionamos três iniciativas de mulheres que passaram pela experiência do câncer e, em contextos distintos, canalizaram seus esforços a ações que propunham mitigar as consequências da doença em suas vidas. Em cada caso, um novo olhar para si e diferentes estratégias para se ressignificar. Em dois desses casos, os artefatos mediam diretamente as ações.

\section{Pesquisa empírica}

\section{Procedimentos}

A pesquisa doutoral que compreende as reflexões aqui apresentadas é de natureza qualitativa. Parte da pesquisa empírica vem se dando por meio de coleta de dados em ambiente virtual, de maneira 
exploratória e investigativa. Para tal, temos acessado blogs, fóruns, redes sociais e sites comerciais, de modo a identificar estratégias, artefatos e debates promovidos em torno da problemática do câncer de mama e do convívio com a doença. Um outro recurso do qual temos lançado mão são as observações participantes, realizadas em um grupo de apoio a pacientes com câncer. Por meio dessas abordagens, buscamos identificar tecnologias de gênero (Lauretis, 1994) e perceber estratégias que as mulheres utilizam para lidar com o gendramento do mundo e, ao mesmo tempo, escapar deste lugar engendrado, à medida que ele se apresenta como opressão. Trata-se, sobretudo, de experiências nas quais as mulheres exercem um protagonismo no que se refere às decisões sobre seus corpos e imagens pessoais.

\section{Transformações corporais: reverter ou acolher?}

As feias caem em desgraça, até que o século $X X$ as resgate: todas as mulheres podem ser belas. É uma questão de maquiagem e de cosméticos, dizem as revistas femininas. De vestuário também, daí a importância da moda, que, num misto de prazer e tirania, transforma modelando as aparências. Questão de vontade, segundo Marcelle Auclair da revista Marie Claire. Em suma, ninguém tem o direito de ser feia. A estética é uma ética. (PERROT, 2007, p. 50).

Na pesquisa exploratória em ambiente virtual, temos realizado uma arqueologia em torno da temática do câncer de mama. Nesse ambiente, as informações encontradas apontam, via de regra, para soluções que objetivam restaurar a imagem de corpo que foi comprometida. De modo geral, a divulgação, venda e compartilhamento de produtos, serviços e iniciativas que apoiam as mulheres por meio de sites e redes sociais exploram o resgate da imagem idealizada do corpo feminino. Por outro lado, as iniciativas que destoam dessas práticas heteronômicas ainda se apresentam timidamente.

Em nosso primeiro exemplo, destacamos o projeto "Mamas do amor", desenvolvido por Fernanda Aguiar, ex-paciente de câncer de mama. Além de ensinar as mulheres a produzir suas próprias próteses externas com materiais de baixo custo (meia-calça e alpiste), a associação conta com 80 voluntárias que produzem e enviam próteses feitas artesanalmente com esse material para mulheres em tratamento. As próteses são destinadas a mulheres que não têm condições fisiológicas ou econômicas de se submeter à cirurgia de reconstrução. Para muitas delas, devido ao custo, mesmo a prótese externa de silicone não pode ser considerada uma opção. 

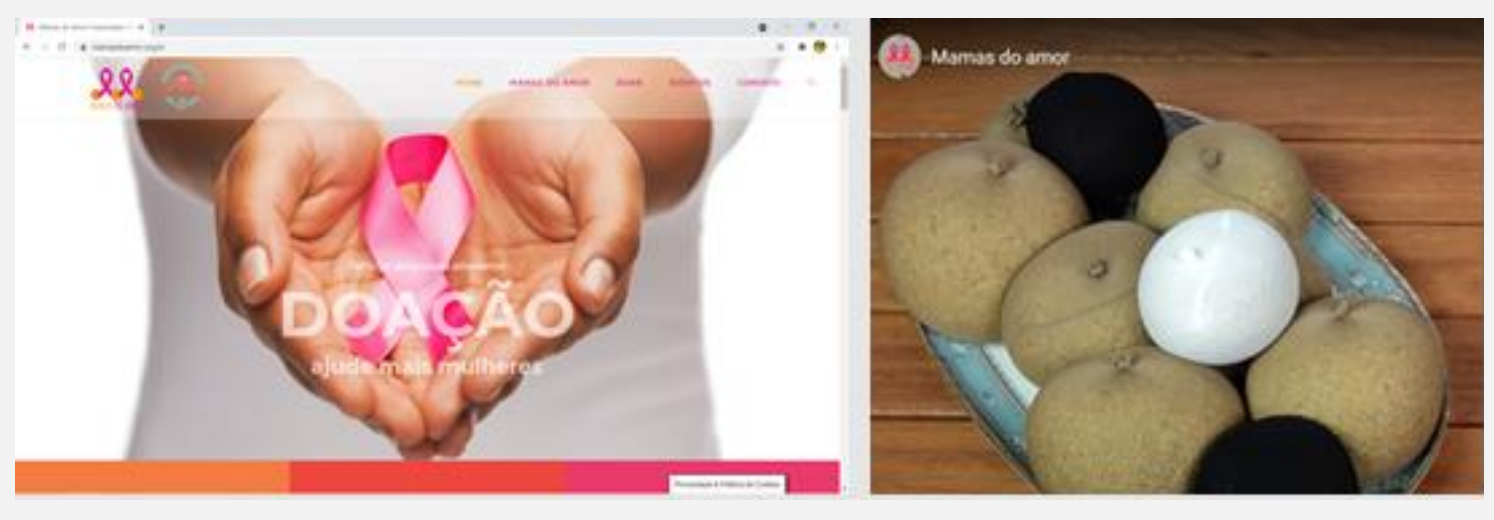

Figura 1. Projeto “Mamas do Amor" (website e próteses externas fabricadas pelas colaboradoras do projeto) Fonte: https://www.mamasdoamor.org.br/

Por outro lado, algumas iniciativas de transgressão ao discurso hegemônico também despontam. Aqui, destacamos uma coleção de trajes de banho pensada para mulheres que já tiveram câncer de mama e perderam uma das mamas. A coleção se chama Monokini $\mathbf{2 . 0}$ e foi criada por um grupo de estilistas finlandeses. Idealizada por Elina Halttunen, também ex-paciente de câncer de mama, “Monokini 2.0 é um projeto de arte que se posiciona sobre a ideia estreita da cultura comercial ocidental sobre a aparência ideal das mulheres e se esforça para expandir a ideia do que é considerado belo no corpo feminino" (MONOKINI 2.0, 2021).
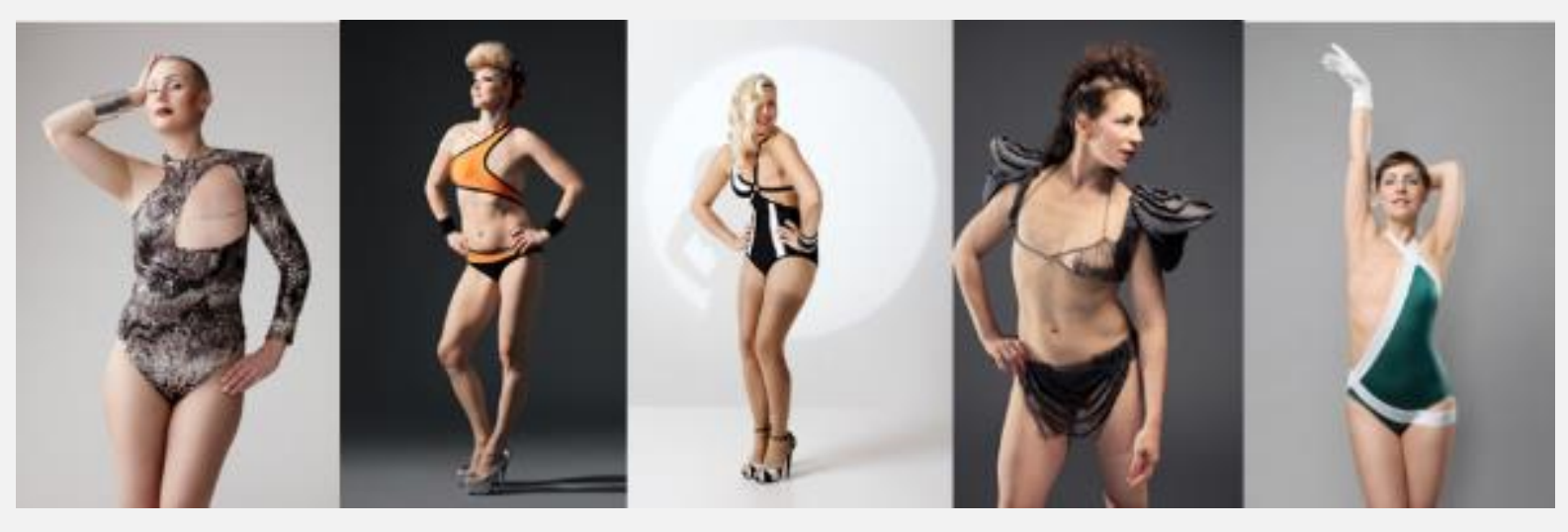

Figura 2. Coleção de trajes de banho "Monokini 2.0"

Fonte: http://www.monokini2.com/

Embora o senso comum legitime o esforço empreendido para "trazer de volta" parte do corpo ou da imagem comprometida, a necessidade de atender a certos padrões - que está posta e naturalizada em nossas práticas - pode pesar excessivamente, quando atender a essa idealização deixa de ser uma possibilidade. Assim, mesmo partindo de pontos de vista contrastantes, experiências como o Mamas do amor - com próteses de baixo custo e que modelam o corpo sem a agressão da cirurgia reparadora - e o Monokini 2.0 - que assume a representação do corpo real, maculado pela doença, 
procurando a beleza em configurações que o senso comum reputaria como abjeção - configuram-se, cada uma a seu modo, como estratégias de transgressão. Em ambos os casos, vemos os artefatos como mediadores dos discursos em questão.

\section{A subjetividade do corpo (i)material}

Outra estratégia de coleta de dados empreendida para a tese se constituiu a partir de observações participantes junto ao GAAPAC (Grupo de apoio e autoconhecimento para pessoas com câncer). Fundada por Edna Bispo, ex-paciente de câncer, trata-se de uma associação sem fins lucrativos, que se baseia na metodologia criada pelo oncologista e radioterapeuta Dr. Carl Simonton. A metodologia "utiliza a técnica de relaxamento/visualização, que consiste em criar imagens mentais para comunicar-se com o corpo, informando o que dele queremos e conduzindo-o para uma vida saudável" além disso, "associa procedimentos terapêuticos que estimulam a mente e a afetividade, modulando significativamente a relação imunológica e comportamental, desencadeando um processo interno de cura". (GAAPAC, 2021)

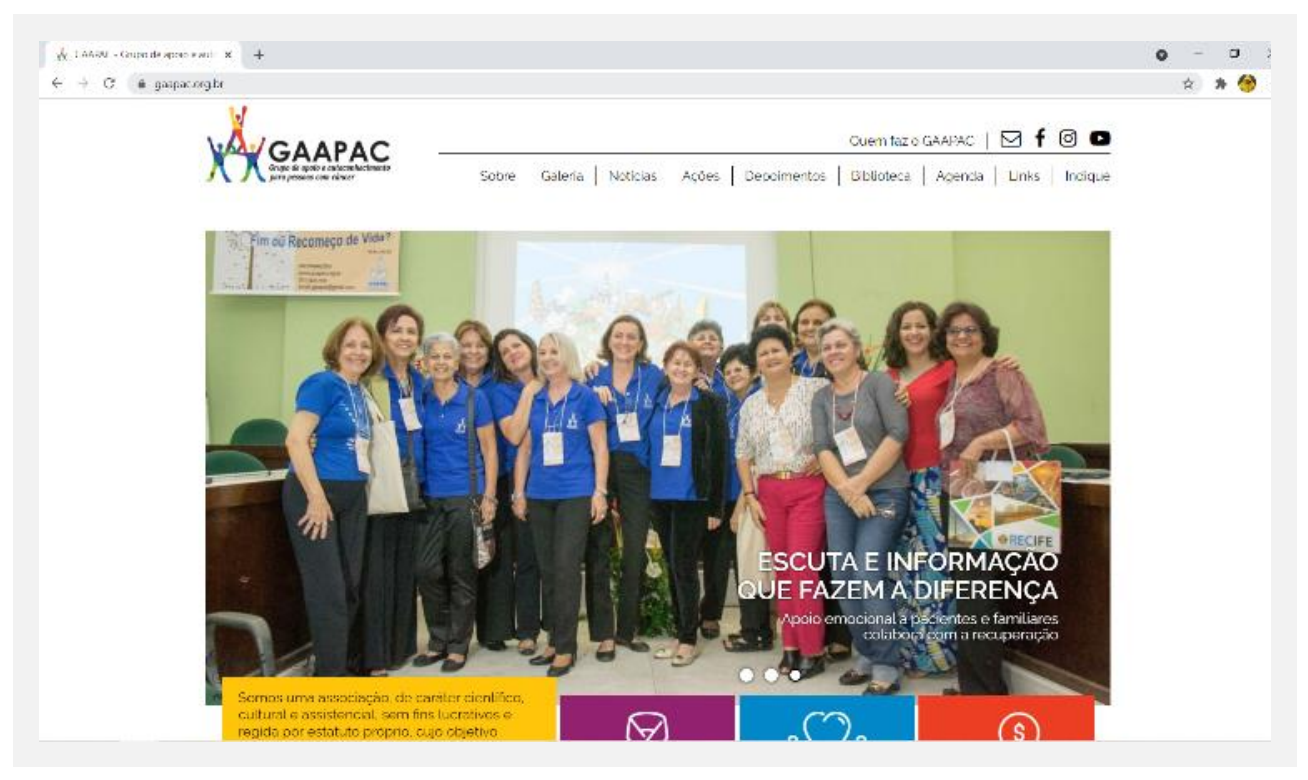

Figura 3. Grupo de voluntárias e integrantes do GAAPAC (Grupo de apoio e autoconhecimento para pessoas com câncer) Fonte: https://gaapac.org.br/

Desde 1992, o grupo apoia pacientes com câncer através de rodas de diálogo e compartilhamento, além de promover outras vivências com seus integrantes. A condução do grupo é feita por mulheres (psicólogas, médicas, enfermeiras, etc.). Nas reuniões, as reflexões são marcadas pelo convite ao autoconhecimento e o corpo é abordado de uma perspectiva holística, buscando integrá-lo à mente, espírito e emoções. 
Em nossas vivências com o grupo, notamos que o mesmo é regido pela concepção de que a doença é a forma que o corpo encontra para convidar o indivíduo a olhar para si e buscar novas possibilidades de vida. Ali, não se discute o corpo como vitrine para o outro, mas como templo de si mesmo. "Força para os glóbulos brancos!" são palavras de ordem ao fim de cada encontro. Interpretamos este, entre outros rituais do grupo, como afirmação do viver, a despeito das demandas sociais que existam sobre os integrantes e sobre seus corpos. O trabalho comunicacional e simbólico realizado nas sessões nos pareceu direcionado a uma perspectiva do corpo não apenas enquanto matéria, mas enquanto subjetividade e espiritualidade. A nosso ver, essa também é uma maneira de transgredir.

\section{Discussões}

Nesta pesquisa, a questão de gênero (e aí se incluem as relações assimétricas de poder) se expressa na temática da imagem corporal - sobretudo feminina - e na discussão sobre os artefatos voltados às mulheres. Também estão contempladas as idealizações sobre os corpos femininos, que resultam da visão hegemônica sobre a mulher e seu papel na família e na sociedade em geral. Por se concentrar no campo simbólico do design e não diretamente na prática projetual, as ferramentas de pesquisa que temos buscado visam compreender o discurso vigente e questionar o que está estabelecido, percebendo e refletindo sobre as tecnologias de gênero e seus efeitos.

Os exemplos que mencionamos apontam em diferentes sentidos: (i) um contexto no qual se busca reabilitar uma imagem comprometida pelo câncer; (ii) um contexto no qual a padronização é criticada, uma vez que enfatiza os estereótipos que reforçam a opressão das mulheres e (iii) um contexto em que a imagem é disposta em segundo plano, prevalecendo a aceitação integral de si. Por meio da pesquisa empírica, temos observado que o poder do discurso patriarcal e hegemônico se revela na materialidade de diversos artefatos direcionados às mulheres que passam pela experiência do câncer, incentivando e priorizando certos padrões corporais em detrimento de toda uma diversidade humana. Contudo, a partir da apreciação preliminar das informações coletadas, vemos que despontam (de maneira consciente ou não) iniciativas de transgressão a tal discurso. Observamos, ainda, que apesar das relações de poder estabelecidas, a consciência da lógica vigente possibilita que certos discursos de resistência sejam operacionalizados.

\section{Conclusões e considerações finais}

Lauretis (1994) afirma que "a construção do gênero é o produto e o processo tanto da representação quanto da autorrepresentação." Nesse sentido, destacamos algumas das diferentes experiências que apresentam caminhos para a construção de certas práticas, a saber: (i) a proposição de iniciativas 
acessíveis que visam atingir ou recuperar uma imagem de corpo; (ii) a operacionalização de práticas disruptivas, propondo uma quebra mais efetiva em relação à estética normativa do corpo e (iii) o compartilhamento terapêutico de experiências pessoais, concebendo o corpo como um elemento integrado a atributos subjetivos e imateriais do indivíduo. A partir dessas experiências, nos propusemos a revelar estratégias de transgressão empreendidas pelas mulheres como forma de enfrentamento ao câncer, contrapondo-se aos discursos opressivos no que diz respeito ao corpo feminino. Esperamos, com isso, provocar reflexões sobre a contribuição do design enquanto tecnologia de gênero nesse processo, tanto no campo da linguagem e do discurso, quanto através de suas práticas projetuais.

Ao longo da pesquisa, temos procurado incluir as mulheres e suas diferentes perspectivas em nossas reflexões, seja pelo compartilhamento de experiências pessoais em grupos de apoio, seja através de iniciativas divulgadas em sites e redes sociais, ou ainda na voz daquelas mulheres que, transgredindo o discurso vigente, utilizam seus corpos para romper com o silêncio. No entanto, apesar de nossos esforços para integrar tantas vozes quanto possível, estamos cientes de que ao fim do processo, teremos apenas um pequeno recorte de tudo que se apresenta na imensa gama de possibilidades do universo feminino. Ressaltamos que, até aqui, temos tratado apenas do sistema sexo-gênero. Na prática, é preciso considerar outras relações de poder como raça e classe social, que emergem desse sistema.

Cabe-nos, por fim, destacar a relevância de uma prática projetual polifônica, através da qual um discurso inclusivo quanto às distintas representações de corpos, artefatos e contextos sociais seja algo inerente e natural. A nosso ver, na prática do design, as escolhas se tornam invisíveis quando somente uma via de abordagem para problemas projetuais envolvendo imagens e discursos sobre o corpo ou sobre o papel das mulheres é considerada. Obviamente, não podemos nem devemos abstrair o que está posto. O equívoco, entretanto, está em nos limitarmos a propor soluções que apenas reforçam um discurso opressor e que não ultrapassam os limites das formulações heteronômicas naturalizadas socialmente.

\section{Agradecimentos}

À Universidade Federal de Pernambuco ${ }^{1}$

À Carleton University| Canada² 


\section{Referências}

LAURETIS, Teresa De. A tecnologia do gênero. Tradução de Suzana Funck. In: HOLLANDA, Heloisa Buarque (Org.). Tendências e impasses: o feminismo como crítica da cultura. Rio de Janeiro: Rocco, 1994. p. 206-242.

PERROT, Michelle. Minha História das Mulheres. Tradução: Angela M. S. Corrêa. São Paulo: Contexto, 2007.

<https://gaapac.org.br/sobre/>. Acesso em: 15 ago. 2021.

<https://www.mamasdoamor.org.br/>. Acesso em: 15 ago. 2021.

<http://www.monokini2.com/>. Acesso em: 15 ago. 2021.

\footnotetext{
${ }^{1}$ que através do PPG-Design e seus docentes, tem incentivado e viabilizado minha pesquisa doutoral e esta publicação.

2 que por meio do Programa GDS (Gendered Design in STEAM), com recursos do IDRC (International Development Research Centre), tem financiado o projeto de pesquisa que coordeno, intitulado "Studying the use of artifacts to rebuild self-image and identity among female breast cancer survivors in Brazil", corroborando para que o produto das reflexões iniciadas com esta tese extrapolem as fronteiras de nossa pesquisa doutoral.
} 